\title{
CLINICAL STUDY OF VISUAL OUTCOME AND COMPLICATIONS FOLLOWING NEODYMIUM: YTTRIUM- ALUMINIUM-GARNET (ND: YAG) LASER POSTERIOR CAPSULOTOMY FOR POSTERIOR CAPSULAR OPACIFICATION
}

\author{
Mayuri Borgohain ${ }^{1}$, Gautam Paul 2
}

1 Former Postgraduate Trainee, Department of Ophthalmology Silchar Medical College and Hospital, Silchar. ${ }^{2}$ Associate Professor, Department of Ophthalmology Silchar Medical College and Hospital, Silchar.

\section{ABSTRACT}

\section{BACKGROUND}

The present study of "visual outcome and complication following Nd: YAG laser posterior capsulotomy" was conducted in Silchar Medical College and Hospital, over a period of one year from September, 2014 to August, 2015.

\section{MATERIALS AND METHODS}

The study was conducted at Silchar Medical College and Hospital, Silchar from September, 2014 to August, 2015. Visual outcome and complications following Nd: YAG laser capsulotomy for posterior capsular opacification was studied in 100 eyes of 100 patients.

\section{RESULTS}

Improvement in visual acuity was found to be excellent in this present study. Significant improvement in visual acuity was seen in 82 cases (82\%) with 6/18 vision or more. Out of these, visual acuity of 6/6 was seen in 40 cases (40\%). Rest of the cases could not be improved to $6 / 6$ because of high astigmatism. Incidence of various complications found after Nd: YAG laser posterior capsulotomy were, immediate raised intraocular pressure in 30 cases (30\%), mild anterior uveitis in 19 cases (19\%), intraocular lens pitting in 12 cases (12\%), anterior hyaloid membrane rupture in 8 cases (8\%).

\section{CONCLUSION}

$\mathrm{Nd}$ : YAG laser posterior capsulotomy is a very economical, convenient, fast and non-invasive OPD procedure for posterior capsular opacification with immediate results. Although safe, Nd: YAG laser capsulotomy carries risks. However, these can be minimised when correctly done with proper patient selection, thorough fundus examination and at least three months after the cataract surgery.

\section{KEYWORDS}

Nd: YAG Laser, Posterior Capsulotomy, PCO.

HOW TO CITE THIS ARTICLE: Borgohain M, Paul G. Clinical Study of Visual outcome and complications following neodymium: yttrium-aluminium-garnet (ND:YAG) laser posterior capsulotomy for posterior capsular opacification. J. Evolution Med. Dent. Sci. 2017;6(9):733-737, DOI: 10.14260/Jemds/2017/158

\section{BACKGROUND}

Cataract is the chief cause of avoidable blindness in the world. ${ }^{1}$ Extracapsular cataract extraction (ECCE) or phacoemulsification with posterior chamber intraocular lens implant (PCIOL) is the most frequent surgical technique. ${ }^{2}$ However, posterior capsular opacification (PCO), which is also termed secondary cataract, is a common long-term complication of modern cataract surgery. ${ }^{3}$ Advantages in surgical techniques, intraocular lens materials and designs have reduced the PCO rate, but it is still a significant problem. The current treatment of choice for PCO is Neodymiumdoped Yttrium-Aluminium-Garnet (labelled as Nd: YAG) laser capsulotomy, which is an effective, safe, non-invasive procedure that does not require patient hospitalisation. 4,5 However, Nd: YAG laser posterior capsulotomy can be associated with significant complications. The purpose of the study is to evaluate the visual outcome and the complications following $\mathrm{Nd}$ : YAG laser posterior capsulotomy.

Financial or Other, Competing Interest: None.

Submission 21-12-2016, Peer Review 15-01-2017,

Acceptance 21-01-2017, Published 30-01-2017.

Corresponding Author:

Dr. Mayuri Borgohain,

Kailashpur, Hengrabari, Guwahati-36,

Kamrup, Assam, India.

E-mail: mayuriborgohain1986@gmail.com

DOI: $10.14260 /$ jemds $/ 2017 / 158$

Aims and Objectives

This Study Aims to Find Out

1. The visual outcome following Nd: YAG laser posterior capsulotomy.

2. The different complications following Nd: YAG laser posterior capsulotomy.

3. The incidence of the complications.

\section{MATERIALS AND METHODS}

\section{Source of Data}

Nd: YAG laser capsulotomy was carried out in 100 eyes of 100 patients. The materials for the present study will be drawn from the patients attending outpatient department of Ophthalmology at SMCH, Silchar from September, 2014 to August, 2015. The criterion for selection of patient was significant posterior capsular opacification causing decrease in visual acuity. Approval for the study was obtained from the institution's ethical review board.

\section{Inclusion Criteria}

1. Decrease in vision by at least $\leq 6 / 9$ on Snellen's chart.

2. Posterior capsular opacification at least 3 months after cataract surgery.

\section{Exclusion Criteria}

1. Age less than 15 years.

2. Eyes with subluxated lens. 
3. Eyes with aphakia.

4. Cases with post-op complications like endophthalmitis.

5. Uncooperative patients with pre-existing corneal scars, irregularities or oedema that interfere with target visualisation.

6. PCO associated with pre-existing cystoid macular oedema or other fundus pathology that likely to reduce the visual acuity.

7. Patients with pre-existing raised intraocular pressure.

Detailed clinical examination, visual acuity testing with Snellen's chart, slit-lamp examination, measurement of IOP with Goldman applanation tonometer, fundus examination and B scan ultrasound were done. Random blood sugar was done as routine investigation to all patients. Finally, informed consents were taken before doing the procedure. Nidek YC $1800 \mathrm{Q}$ and Abraham lens were used for the procedure.

Topical proparacaine hydrochloride ophthalmic solution $5 \%$ was used as anaesthetic and $2 \%$ hypromellose gel used in the contact lens as coupling media. Minimal energy level (0.5$1 \mathrm{~mJ}$ ) was used initially and may increase gradually up to 2.5 $\mathrm{mJ}$. An opening of 3-4 $\mathrm{mm}$ was produced in the posterior capsule. Intraocular pressure was examined on the same day at 1 hour and 4 hours following the procedure. All patients were routinely given topical antibiotic-steroid combination drops. The patients were discharged on the same day. Patients were followed up after 1 week, 2 weeks and then at 1 month. On each followup visit, patients were examined for visual acuity, intraocular pressure, corneal burn, inflammation of iris, hyphaema, intraocular lens pitting and posterior segment for anterior hyaloid membrane rupture, cystoid macular oedema, endophthalmitis and retinal detachment. The patients were given topical timolol maleate $0.5 \%$ eye drops twice daily if the post laser IOP is $>21 \mathrm{mmHg}$ 1 week after the procedure.

\section{RESULTS}

In the present study, 100 eyes of 100 patients with pseudophakia and posterior capsular opacification undergoing Nd: YAG laser capsulotomy in the Department of Ophthalmology was evaluated. The observations done during the study are as follows.

Male and female distribution was 0.61 . The age ranged from 25 to 85 years. Mean age was 64.9 years, an incidental finding as cases were selected on random basis. Fundus was visible in 91 cases and hazy in 9 cases due to presence of thick PCO.

\begin{tabular}{|c|c|c|}
\hline \multirow{2}{*}{$\begin{array}{c}\text { Visual } \\
\text { Acuity }\end{array}$} & Number of Patients \\
\cline { 2 - 3 } & Pre Laser & Post Laser \\
\hline $6 / 6$ & 0 & 40 \\
\hline $6 / 9-6 / 24$ & 34 & 48 \\
\hline $6 / 36-6 / 60$ & 36 & 7 \\
\hline $5 / 60-1 / 60$ & 21 & 0 \\
\hline FC-HM & 9 & 0 \\
\hline \multicolumn{3}{|c|}{ Visual Outcome } \\
\hline
\end{tabular}

\section{Cases Lost to Follow}

Pre YAG visual acuity in 9 patients were hand movement to finger counting, whereas $1 / 60-5 / 60$ in $21,6 / 60$ to $6 / 24$ in $55,6 / 18$ to $6 / 9$ in 15 patients. Visual acuity improved to $6 / 6$ in 40 patients, $6 / 18$ to $6 / 9$ in 42 and $6 / 60$ to $6 / 24$ in 13 patients.

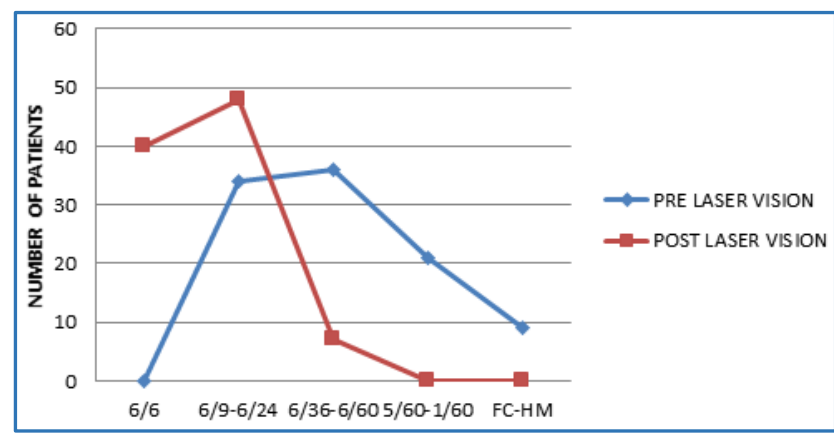

Figure 1. Line Diagram showing Visual Outcome following Nd: YAG Laser Capsulotomy

\begin{tabular}{|c|c|c|c|c|c|c|c|c|c|}
\hline \multirow{3}{*}{$\begin{array}{c}\text { Pre-Laser } \\
\text { Visual } \\
\text { Acuity }\end{array}$} & \multicolumn{8}{|c|}{ Post Laser Visual Acuity } & \multirow{3}{*}{\begin{tabular}{|c|} 
Lost \\
To \\
Followup
\end{tabular}} \\
\hline & 6/ & $6 /$ & 6/ & 6/ & 6/ & 6/ & 6/ & $<6 /$ & \\
\hline & 6 & 9 & 12 & 18 & 24 & 36 & 60 & 60 & \\
\hline$<6 / 60$ & 3 & 7 & 9 & 1 & 4 & 2 & 3 & 0 & 1 \\
\hline $6 / 60$ & 5 & 7 & 2 & 0 & 0 & 2 & 0 & 0 & 2 \\
\hline $6 / 36$ & 8 & 6 & 2 & 0 & 2 & 0 & 0 & 0 & 2 \\
\hline $6 / 24$ & 12 & 1 & 2 & 3 & 0 & 0 & 0 & 0 & 0 \\
\hline $6 / 18$ & 6 & 1 & 0 & 0 & 0 & 0 & 0 & 0 & 0 \\
\hline $6 / 12$ & 5 & 1 & 0 & 0 & 0 & 0 & 0 & 0 & 0 \\
\hline $6 / 9$ & 1 & 0 & 0 & 0 & 0 & 0 & 0 & 0 & 0 \\
\hline \multicolumn{10}{|c|}{ Pattern of Visual Outcome } \\
\hline
\end{tabular}

Pre-laser visual acuity improved from $<6 / 60$ to $6 / 6$ in 3 cases, $6 / 9$ in 7 cases, $6 / 12$ in 9 cases, $6 / 18$ in 1 case, $6 / 24$ in 4 cases, $6 / 36$ in 2 cases, $6 / 60$ in 3 cases. 1 case lost to followup.

Pre-laser visual acuity improved from $6 / 60$ to $6 / 6$ in 5 cases, $6 / 9$ in 7 cases, $6 / 12$ in 2 cases, $6 / 36$ in 2 cases. 2 cases lost to followup.

Pre-laser visual acuity improved from $6 / 36$ to $6 / 6$ in 8 cases, $6 / 9$ in 6 cases, $6 / 12$ in 2 cases, $6 / 24$ in 2 cases. 2 cases lost to followup.

Pre-laser visual acuity improved from $6 / 24$ to $6 / 6$ in 12 cases, $6 / 9$ in case, $6 / 12$ in 2 cases, $6 / 18$ in 3 cases; from $6 / 18$ to $6 / 6$ in 6 cases, $6 / 9$ in 1 case; from $6 / 12$ to $6 / 6$ in 5 cases and $6 / 9$ in 1 case; from $6 / 9$ to $6 / 6$ in 1 case.

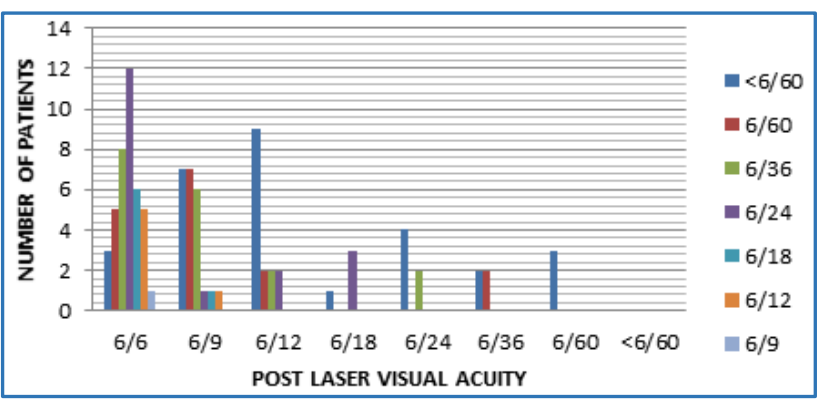

Figure 2. Histogram showing Pattern of Visual Outcome after Nd: YAG Laser Posterior Capsulotomy

\begin{tabular}{|c|c|c|}
\hline Complications & $\begin{array}{c}\text { Number of } \\
\text { Patients }\end{array}$ & \% \\
\hline Corneal Burn & 0 & 0 \\
\hline IRITIS & 19 & 19 \\
\hline Hyphaema & 0 & 0 \\
\hline IOL Pitting & 12 & 12 \\
\hline Anterior Hyaloid Membrane Rupture & 8 & 8 \\
\hline Raised IOP & 30 & 30 \\
\hline
\end{tabular}




\begin{tabular}{|c|c|c|}
\hline CME & 0 & 0 \\
\hline Endophthalmitis & 0 & 0 \\
\hline RD & 0 & 0 \\
\hline No Complication & 25 & 25 \\
\hline Lost to Followup & 5 & 5 \\
\hline Post YAG Laser Complications \\
\hline
\end{tabular}

The patients were evaluated for any complications following Nd: YAG laser posterior capsulotomy and it was found that raised intraocular pressure was the most common complication following the procedure which was seen in 30 (30\%) patients, second most common was the presence of iritis in 19 cases (19\%) followed by intraocular lens pitting in 12 cases $(12 \%)$ and rupture of anterior hyaloid membrane in 8 cases $(08 \%)$. None of the patients showed corneal burn, hyphaema, cystoid macular oedema, endophthalmitis or retinal detachment within 1 month followup period. 24 patients showed no complications, whereas 5 patients lost to follow up.

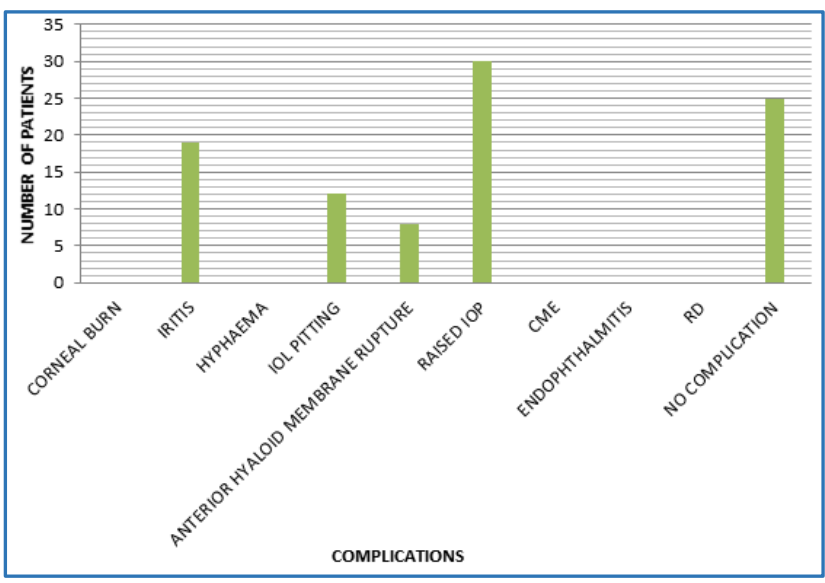

Figure 3. Bar Diagram showing Complications following Nd: YAG Laser Posterior Capsulotomy

\begin{tabular}{|c|c|c|}
\hline \multirow{2}{*}{ Duration } & \multicolumn{2}{|c|}{ Number of Patients } \\
\cline { 2 - 3 } & Raised IOP & Unchanged \\
\hline 1 Hour & 30 & 70 \\
\hline 4 Hour & 28 & 72 \\
\hline 1 Week & 7 & 88 \\
\hline 2 Weeks & 1 & 94 \\
\hline 1 Month & 0 & 95 \\
\hline \multicolumn{2}{|c|}{ Intraocular Pressure Changes } \\
\hline
\end{tabular}

\section{Patients Lost to followup}

The rise in intraocular pressure was seen in $30 \%$ cases $(30$ cases) 1 hour after and in 28\% cases (28\%) 4 hours after Nd: YAG laser capsulotomy, which on treatment returns to prelaser value in $21 \%$ cases after 1 week. $7 \%$ cases ( 7 cases) showed raised IOP even after continued medication for 1 week. After 2 weeks, only 1 case showed raised IOP. But, none of these 7 cases showed persistent rise in intraocular pressure at 1 month followup.

\begin{tabular}{|c|c|c|c|c|c|}
\hline \multirow{2}{*}{$\begin{array}{c}\text { Intraocular } \\
\text { Pressure } \\
\text { (mmHg) }\end{array}$} & $\begin{array}{c}\mathbf{1} \\
\text { Hour }\end{array}$ & $\begin{array}{c}\mathbf{4} \\
\text { Hours }\end{array}$ & $\begin{array}{c}\mathbf{1} \\
\text { Weeks }\end{array}$ & $\begin{array}{c}\mathbf{2} \\
\text { Weeks }\end{array}$ & $\begin{array}{c}\mathbf{1} \\
\text { Month }\end{array}$ \\
\cline { 2 - 6 } Unchanged & 70 & 72 & 88 & 94 & 95 \\
\hline $1-2$ & 27 & 26 & 5 & 1 & 0 \\
\hline $3-4$ & 1 & 0 & 1 & 0 & 0 \\
\hline $5<$ & 2 & 2 & 1 & 0 & 0 \\
\hline \multicolumn{7}{|c|}{ Pattern of Changes in IOP } \\
\hline
\end{tabular}

Out of 100 cases, 70 cases showed no change in intraocular pressure, 27 cases showed increase in intraocular pressure by 1-2 mmHg, 1 case showed rise by 3-4 mmHg and 2 cases showed rise by more than $5 \mathrm{mmHg}$. At the end of 1 week, intraocular pressure was found to be pre-laser value in 88 cases, while 5 cases showed rise in IOP by 1-2 mmHg. Rise in IOP by 3-4 mmHg and more than $5 \mathrm{mmHg}$ was seen in one case each. At the end of 2 weeks, only 1 case showed high IOP, which returned to pre-laser level after 1 month. 5 cases lost to followup.

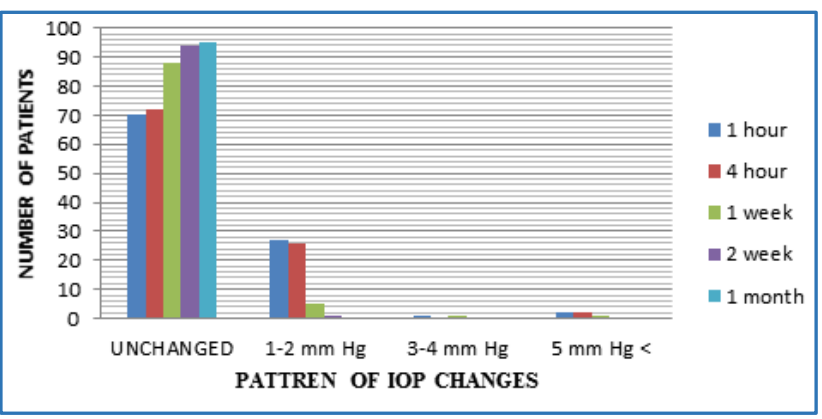

Figure 4. Histogram showing Pattern of Change in Intraocular Pressure after 1 Hour, 4 Hours, 1 Week, 2 Weeks and 1 Month

\begin{tabular}{|c|c|c|}
\hline & Number of Patients & Percentage \\
\hline With Iritis & 19 & 19 \\
\hline No Iritis & 81 & 81 \\
\hline \multicolumn{2}{|c|}{ Incidence of IRITIS } \\
\hline
\end{tabular}

Iritis was the second most common complication found in the present study, with $19 \%$ cases (19 cases).

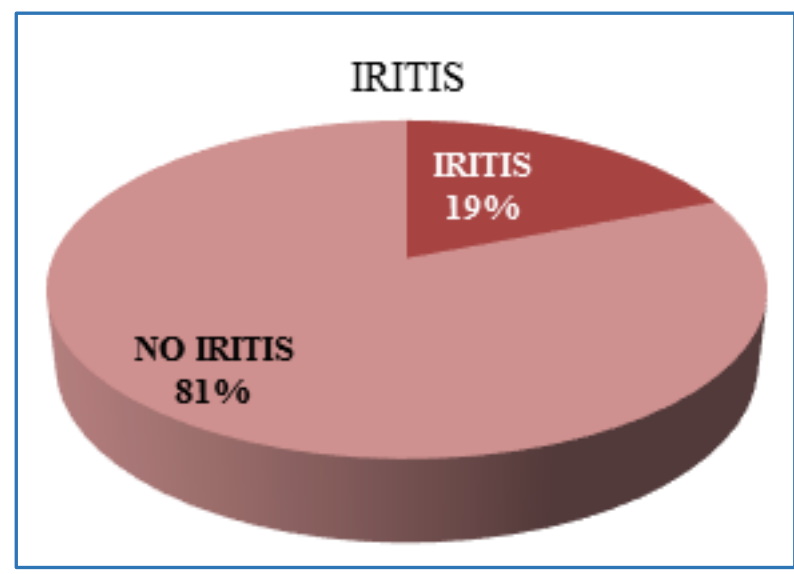

Figure 5. Pie Diagram showing Incidence of Iritis immediately after YAG Laser Capsulotomy

\begin{tabular}{|c|c|c|}
\hline & Number of Patients & Percentage \\
\hline $\begin{array}{c}\text { Cases with } \\
\text { Pitting of IOL }\end{array}$ & 12 & 12 \\
\hline No Pitting & 88 & 88 \\
\hline \multicolumn{2}{|c|}{ Incidence of IOL Pitting } \\
\hline
\end{tabular}

Post YAG laser IOL pitting was seen in $12 \%$ cases $(12$ cases). 


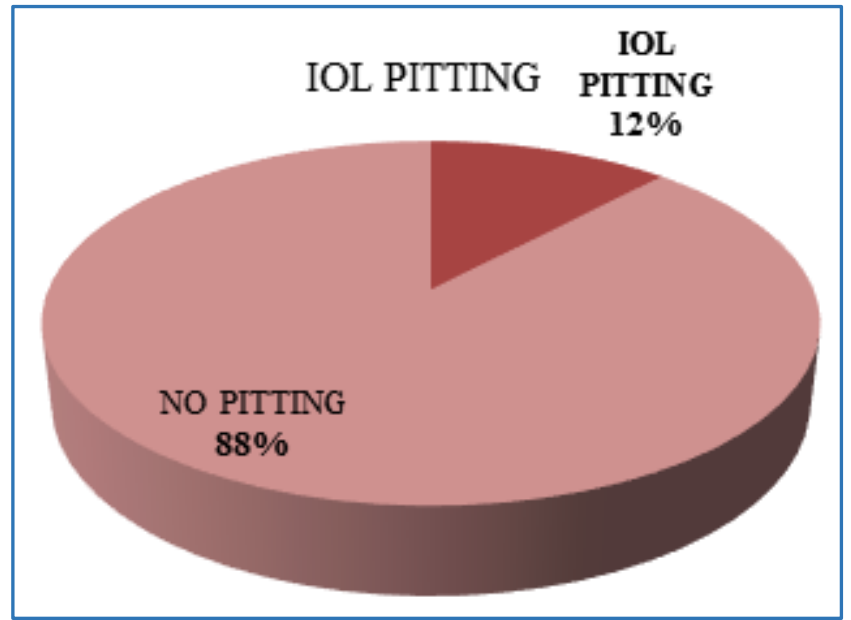

Figure 6. Pie Diagram showing Incidence of Post Laser IOL Pitting

Anterior Hyaloid Membrane Rupture

\begin{tabular}{|c|c|c|}
\hline & Number of Patients & Percentage \\
\hline With AHMR & 8 & 8 \\
\hline No AHMR & 92 & 92 \\
\hline \multicolumn{2}{|c|}{ Incidence of Anterior } \\
Hyaloid Membrane Rupture \\
\hline
\end{tabular}

Anterior hyaloid membrane rupture was seen in $8 \%$ cases (8 cases).

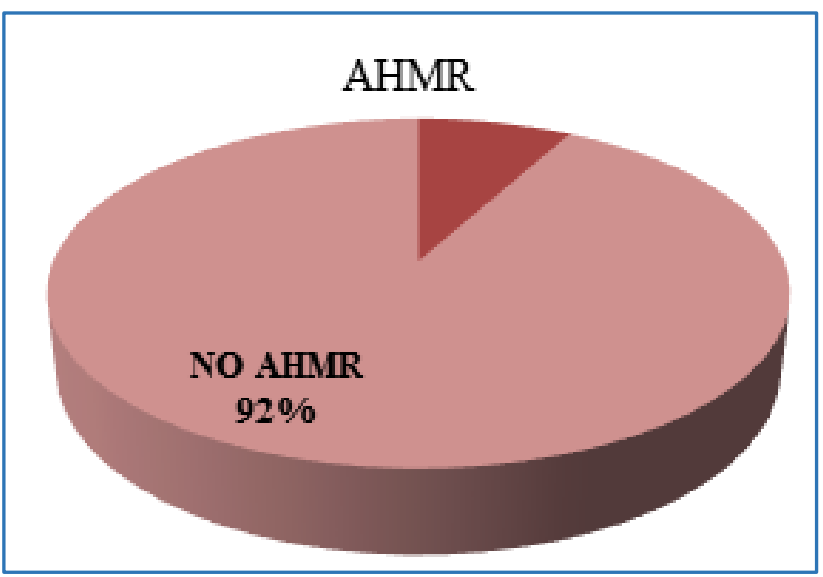

Figure 7. Pie Diagram showing Incidence of Post Laser Anterior Hyaloid Membrane Rupture
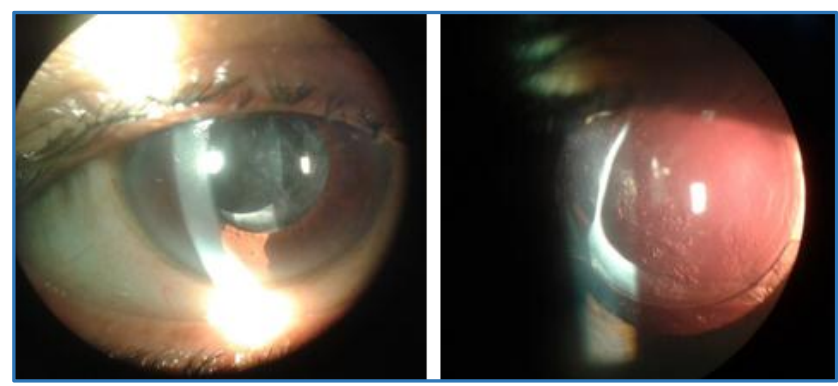

Figure 8. Posterior Capsular Opacification

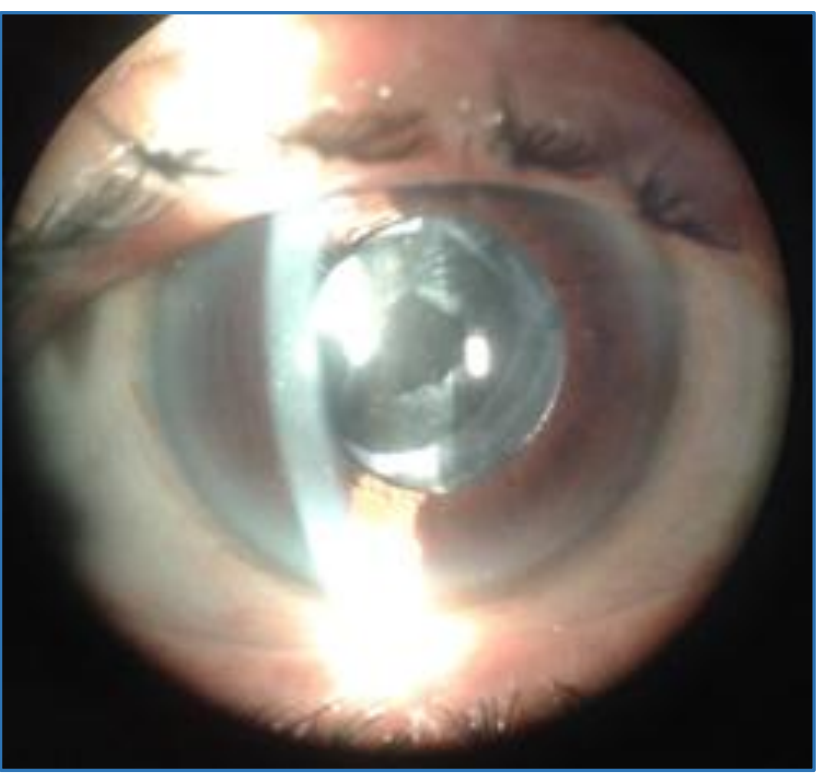

Figure 9. Post Laser

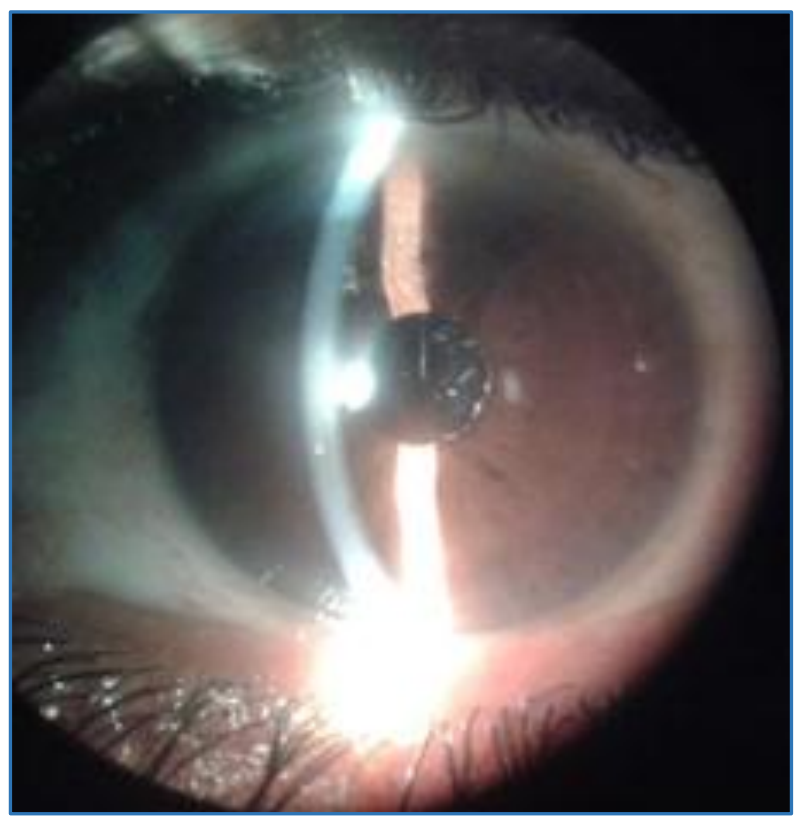

Figure 10. IOL Pitting

\section{DISCUSSION}

Cataract surgery is currently the most common and wellestablished ophthalmic surgical procedure in the world. This procedure involves the extra capsular extraction of the natural opaque lens fibres and implantation of an intraocular lens (IOL), which restores good vision. ${ }^{1}$ Posterior capsular opacification is the most common late complication of uncomplicated cataract surgery with or without intraocular lens implantation. ${ }^{2}$

In this study, the main aim is to evaluate the visual outcome and complications following $\mathrm{Nd}$ : YAG laser capsulotomy in 100 eyes of 100 patients. Visual acuity improved to $6 / 18$ or better in 82 cases $(82 \%)$. None of the cases had visual acuity less than $6 / 60$ after the treatment. Out of 100 eyes of 100 cases, 5 cases lost to followup. Hence, in the present study, improvement in visual acuity was excellent. This was most probably due to high skill, proper patient selection, correct method, good machine and 
exclusion of any abnormality that might reduce post-laser visual acuity. Although, because of high astigmatism most of the cases could not be improved to $6 / 6$.

In this present study, incidence of various complications after Nd: YAG laser posterior capsulotomy were, raised intraocular pressure in 30 cases (30\%), mild anterior uveitis in 19 cases (19\%), intraocular lens pitting in 12 cases (12\%), anterior hyaloid membrane rupture in 8 cases $(8 \%)$. None of the cases showed corneal damage, hyphaema, cystoid macular oedema, endophthalmitis or retinal detachment.

The rise of intraocular pressure was most probably because of presence of cells and flare in the anterior chamber blocking the trabecular meshwork. Most of the cases returned to pre-laser state since all the cases were given topical steroid drops.

In the present study, 19 patients (19\%) had iritis after YAG laser capsulotomy manifested as cells and flare in anterior chamber on slit-lamp examination. They were given topical steroid and reaction had subsided leaving no delayed complication.

In the present study, intraocular lens pitting was seen in $12 \%$ cases (12 cases). This was seen in cases of thick PCO with more number of shots. However, there was no decrease or disturbance in visual acuity with only pitting of IOL.

Anterior hyaloid membrane rupture was seen in 8 cases $(08 \%)$ due to inadvertent shots over anterior vitreous face.

None of the cases showed corneal burn or hyphaema. This was most probably because of high skill with proper focusing and exclusion of uncooperative patients. Cystoid macular oedema, endophthalmitis and retinal detachment were not seen in this present study as less number of shots was used as far as possible; moreover, cases with pre-laser fundus pathology or cases with predisposing factors were excluded from this study. These are contradictory to some studies done earlier.

\section{CONCLUSION}

The posterior capsule opacification is a very common late complication after cataract surgery worldwide and it can be managed safely as an outdoor procedure by Nd: YAG laser posterior capsulotomy improving the visual acuity. It may however require augmentation with optical correction. It is very economical, convenient, fast and non-invasive OPD procedure with immediate results. Although safe, Nd: YAG laser capsulotomy carries risks.

Proper selection of patient is important to reduce these complications. High skill, proper focusing, less number of shots, postponing by at least 3 months after cataract surgery can reduce the incidence of complications. It should be done with caution in patients with increase in axial length, peripheral retinal degeneration and retinal detachment in other eye as these patients are at increased risk of developing retinal detachment. These can also be minimised by minimising energy and number of precisely focused shots.

Hence, Nd: YAG laser capsulotomy remains the most common and safe procedure for the management of PCO when correctly done with proper patient selection, thorough fundus examination and at least three months after the cataract surgery.

\section{REFERENCES}

[1] Thylefors B, Negrel AD, Pararajasegram R. Global data on blindness. Bull World Health Organ 1996;74:319-24.

[2] Natchiar G, Robin AL, Thulasiraj RD, et al. Attacking the backlog of India's curable blind. The Arvind eye hospital model. Arch Ophthalmol 1994;112(7):987-93.

[3] Apple DJ, Solomon KD, Tetz MR, et al. Posterior capsule opacification. Survey of Ophthalmology 1992;37(2):73116.

[4] Polak M, Zarnowski T, Zagórski Z. Results of Nd: YAG laser capsulotomy in posterior capsule opacification. Ann Univ Mariae Curie Sklodowska Med 2002;57(1):357-63.

[5] Burq MA, Taqui AM. Frequency of retinal detachment and other complications after neodymium: Yag laser capsulotomy. J Pak Med Assoc 2008;58(10):550-2. 